\title{
Can Venous Blood Gases Replace Arterial Blood Gases in Diabetic Ketoacidosis/Renal Failure Induced Metabolic Acidosis?
}

\author{
Naveen Mohan", Gireesh Kumar K.P, Sreekrishnan T.P, Ajith Kumar. J, Ajith.V , Bharath Prasad. S, \\ Krupanidhi Karunanithi, Arun Kumar. K
}

Amrita Institute of Medical Sciences \& Research Centre, India

Copyright (C) 2015 by authors, all rights reserved. Authors agree that this article remains permanently open access under the terms of the Creative Commons Attribution License 4.0 International License

\begin{abstract}
The study aims to identify the correlation between arterial and venous blood gas variables, in patients with metabolic acidosis secondary to renal failure and/or diabetic ketoacidosis(DKA). Paired arterial and venous blood samples of 100 patients, with metabolic acidosis resultant to renal failure and/or diabetic ketoacidosis during 2009-2011, were analyzed and the correlation between the variables were assessed using SPSS software, applying Pearson's product moment correlation coefficient, Linear regression, Statistical parameter $\mathrm{R}^{2}$ and Chi-square test. Results: Mean $\mathrm{ABG}$ values for $\mathrm{pH}, \mathrm{HCO} 3, \mathrm{pCO} 2$ and lactate were $(7.29+/-0.448,12.12+/-2.61,25.2+/-4.0$ and 5.39 $+/-1.95$ respectively) and mean VBG values for the same were $(7.292+/-0.0451,12,23+/-2.55,27.8+/-3.9$, and 5.19 $+/-1.81)$. Pearson product moment coefficient for $\mathrm{pH}, \mathrm{HCO} 3$, pCO2 and lactate were $0.919,0.967,0.966$ and 0.924 , with $\mathrm{p}$ $<0.001$. Percentage variation in $\mathrm{ABG}$ as explained by VBG for $\mathrm{pH}=84.4 \%, \mathrm{HCO} 3=93.6 \%, \mathrm{pCO} 2=93.2 \%$ and lactate $=$ $85.4 \%$. Regression equations to predict arterial from venous values:-Arterial $\mathrm{pH}=0.631+0.913 \times$ venous $\mathrm{pH}\left(\mathrm{R}^{2}=0.844\right)$, Arterial $\mathrm{HCO} 3=0.990 \times$ venous $\mathrm{HCO} 3\left(\mathrm{R}^{2}=0.936\right)$, Arterial $\mathrm{pCO} 2=-2.546+0.997 \times$ venous $\mathrm{pCO} 2\left(\mathrm{R}^{2}=0.932\right)$, Arterial lactate $=0.993 \mathrm{x}$ venous lactate $\left(\mathrm{R}^{2}=0.854\right)$. Arterial and venous blood gas values showed significant correlation coefficient for $\mathrm{pH}, \mathrm{HCO} 3, \mathrm{pCO} 2$ and lactate. Hence, VBG may be used as an alternative to $A B G$ in the initial management metabolic acidosis secondary to diabetic ketoacidosis and/or renal failure.
\end{abstract}

Keywords Renal Failure, Diabetic Keto Acidosis, Metabolic Acidosis, Venous Blood Gas, Arterial Blood Gas

\section{Background}

Metabolic acidosis resulting from renal failure and/or diabetic ketoacidosis (DKA) is detected through arterial blood gases (ABG). Arterial blood gas sampling is invasive; involving patient discomfort, arterial injury, thrombosis or embolism, hematoma, aneurysm, reflex sympathetic dystrophy, [1-3] increased number of penetrations and possibility of needle prick injury to medical personnel. Various studies have revealed significant correlation between arterial and venous blood gas(VBG) values, especially $\mathrm{pH}, \mathrm{pCO} 2, \mathrm{HCO} 3$ and lactate with $\mathrm{p}$ value $<0.001$ in all instances, [4-8] indicating the significance of $\mathrm{VBG}$ sampling as an alternative to $\mathrm{ABG},[4-16]$ despite some reservations, $[5,17,18]$. Our study is intended to identify the significance of VBG as an alternative to ABG for detecting metabolic acidosis in the emergency intensive care unit (ICU).

\section{Methods}

One hundred patients with proven metabolic acidosis resultant to renal failure and/or diabetic ketoacidosis admitted to the emergency intensive care unit of a referral hospital at Kochi during 2009-2011, meeting the inclusion criteria were selected for the study. Inclusion criteria includes patients with $\mathrm{pH}<7.35$ and $\mathrm{HCO} 3<18$ with or without comorbidities.

Paired arterial blood gas samples were collected from the radial artery and venous blood gas samples from adjacent veins (immediately after first intravenous cannulation before any drug or fluid administration) and analyzed using the ABG analyzer. All variables of arterial blood gases were compared with corresponding variables of venous blood, and the correlation between the variables were studied using SPSS software, applying Pearson's product moment correlation coefficient, linear regression, statistical parameter $\mathrm{R}^{2}$ and Chi-square test.

\section{Results and Discussion}


- $\quad$ Out of 100 patients studied, $72(72 \%)$ were males and $28(28 \%)$ were females, generally in the age group of 41-60 years (TABLE 1), with or without comorbidities (TABLE 2).

Table 1. Demographic distribution of patients

\begin{tabular}{|c|c|}
\hline Age & $\mathrm{n}=100$ \\
\hline $0-20$ & 7 \\
\hline $21-40$ & 23 \\
\hline $41-60$ & 53 \\
\hline $61-80$ & 17 \\
\hline$>80$ & 1 \\
\hline
\end{tabular}

Table 2. Demographics of comorbidities

\begin{tabular}{|c|c|}
\hline Co morbidities & Patients \\
\hline Diabetes Mellitus & 60 \\
\hline Hypertension & 27 \\
\hline Dyslipidemia & 17 \\
\hline Chronic kidney disease & 15 \\
\hline Chronic liver disease & 13 \\
\hline
\end{tabular}

- $\quad$ Eighty patients $(80 \%)$ had metabolic acidosis due to renal failure and $20(20 \%)$ due to diabetic ketoacidosis.

- Most common diseases causing renal failure and diabetic ketoacidosis were urosepsis 22(22\%), pneumonia $22(22 \%)$ and gastrointestinal sepsis 21(21\%).

- Mean arterial and venous blood gas values for variables- $\mathrm{pH}, \mathrm{HCO} 3, \mathrm{pCO} 2$ and lactate are listed (TABLE 3).

Table 3. Mean arterial \& venous blood gas values

\begin{tabular}{|c|c|c|}
\hline Variables & ABG(Mean+/-SD) & VBG (Mean+/- SD) \\
\hline $\mathrm{pH}$ & $7.29+/-0.0448$ & $7.292+/-0.0451$ \\
\hline $\mathrm{HCO} 3$ & $12.12+/-2.61$ & $12.23+/-2.55$ \\
\hline $\mathrm{pCO}_{2}$ & $25.2+/-4$ & $27.8+/-3.9$ \\
\hline Lactate & $5.39+/-1.95$ & $5.19+/-1.81$ \\
\hline
\end{tabular}

- Mean arterial and venous blood gas values of $\mathrm{pH}$, $\mathrm{HCO} 3, \mathrm{pCO} 2$ and lactate exhibited significant correlation as explained by Pearson product moment coefficient of 0.919(FIGURE 1), 0.967(FIGURE 2) 0.966(FIGURE 3) and 0.924 (FIGURE 4) respectively, with $\mathrm{p}<0.001$ in all instances (TABLE 4).

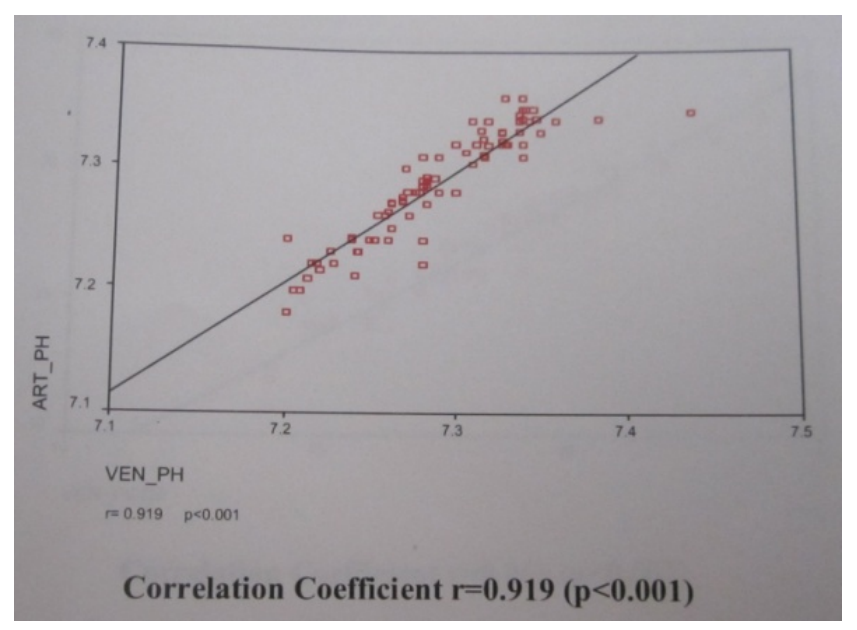

Figure 1. Correlation of arterial and venous $\mathrm{pH}$

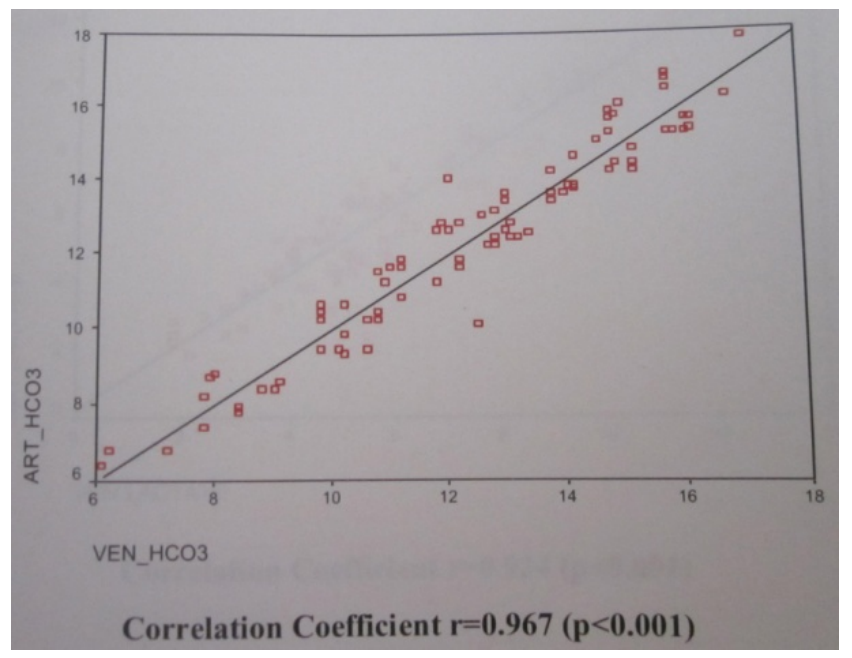

Figure 2. Correlation of arterial and venous $\mathrm{HCO} 3$

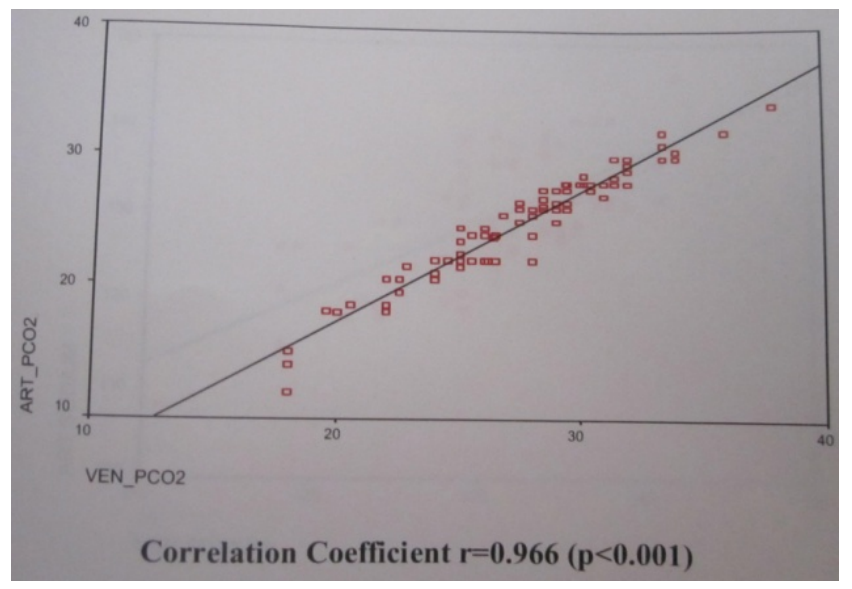

Figure 3. Correlation of arterial and venous $\mathrm{pCO} 2$ 


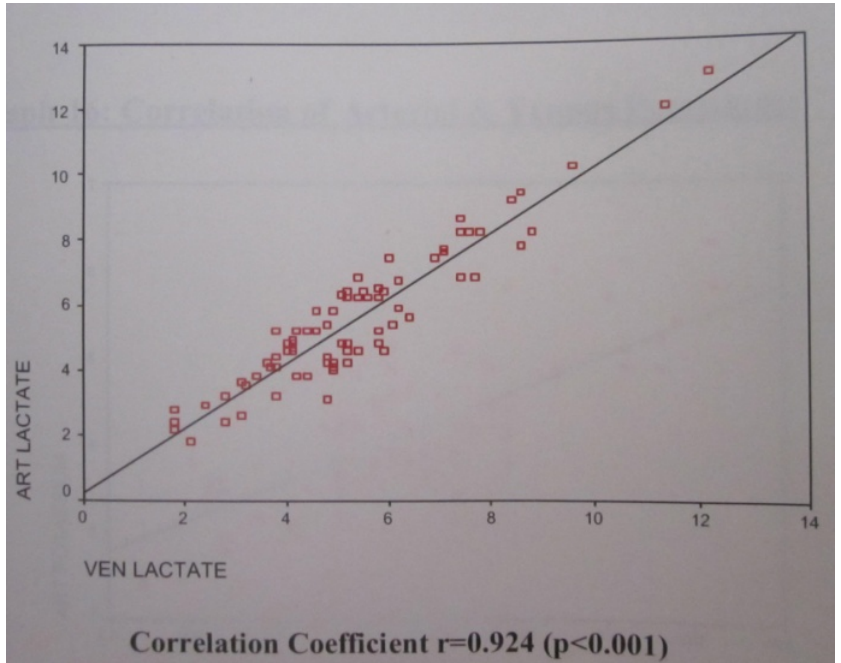

Figure 4. Correlation of arterial and venous lactate

Table 4. Correlation coefficient between ABG and VBG with respect to different variables

\begin{tabular}{|c|c|c|}
\hline Variables & $\mathrm{r}=$ correlation coefficient & P value \\
\hline $\mathrm{pH}$ & 0.919 & $<0.001$ \\
\hline $\mathrm{HCO} 3$ & 0.967 & $<0.001$ \\
\hline $\mathrm{pCO}_{2}$ & 0.966 & $<0.001$ \\
\hline $\mathrm{Na}^{+}$ & 0.703 & $<0.001$ \\
\hline $\mathrm{K}^{+}$ & 0.776 & $<0.001$ \\
\hline $\mathrm{Cl}^{-}$ & 0.525 & $<0.001$ \\
\hline Anion gap & 0.577 & $<0.001$ \\
\hline Lactate & 0.924 & $<0.001$ \\
\hline
\end{tabular}

- Based on these results regression equations were derived, to predict arterial values from venous values as follows:-

$$
\begin{array}{ll}
\text { - } & \text { Arterial } \mathrm{pH}=0.631+0.913 \times \text { venous } \mathrm{pH} \\
& \left(\mathrm{R}^{2}=0.844\right) \\
\text { - } & \text { Arterial HCO3 }=0.990 \times \text { venous } \mathrm{HCO} 3 \\
& \left(\mathrm{R}^{2}=0.936\right) \\
\text { - } & \text { Arterial } \mathrm{pCO} 2=-2.546+0.997 \times \text { venous } \\
& \mathrm{pCO} 2\left(\mathrm{R}^{2}=0.932\right) \\
\text { - } & \text { Arterial lactate }=0.993 \times \text { venous lactate } \\
& \left(\mathrm{R}^{2}=0.854\right)
\end{array}
$$

- Percent of variance (R2) in arterial blood gases for $\mathrm{HCO} 3, \mathrm{PCO} 2$, lactate and $\mathrm{pH}$ explained by venous blood gases in our study, was 93.6, 93.2, 85.4 and 84.4 respectively. One of the previous studies showed a percent variance of 95, 88, 95 for $\mathrm{HCO} 3$, PCO2 and $\mathrm{pH}$ respectively, [6].

- Arterial blood gases showed non anion gap metabolic acidosis (NAGMA) in 62 (77.5\%) and high anion gap metabolic acidosis (HAGMA) in 18 $(22.5 \%)$ patients with renal failure, and all $20(100 \%)$ patients with diabetic ketoacidosis had HAGMA, $\mathrm{p}<0.001$. Mixed acid base disorders in the same patient could have brought this bias.
- Venous blood gases showed NAGMA in 49 (61.3\%) of the patients and HAGMA in $31(38.8 \%)$ patients with renal failure, and $2(10 \%)$ patients with diabetic ketoacidosis had NAGMA and 18(90\%) patients with DKA had HAGMA, $\mathrm{p}<0.001$. There seems to be some difference between ABG and VBG in while assessing the type of metabolic acidosis. As anion gap is further dependent on variables like $\mathrm{Na}+, \mathrm{K}+$, $\mathrm{Cl}-$, HCO3, serum albumin etc it can get considerably altered because the correlation coefficients of those variables showed only minimal amount of correlation FIGURE 5,6,7,8. This could possibly explain variations in the type of metabolic acidosis between the arterial and venous blood samples. Further studies are warranted in this direction, possibly by utilizing the lab derived serum values of the electrolytes for anion gap determination, rather than the $\mathrm{ABG}$ analyzer derived electrolyte values.

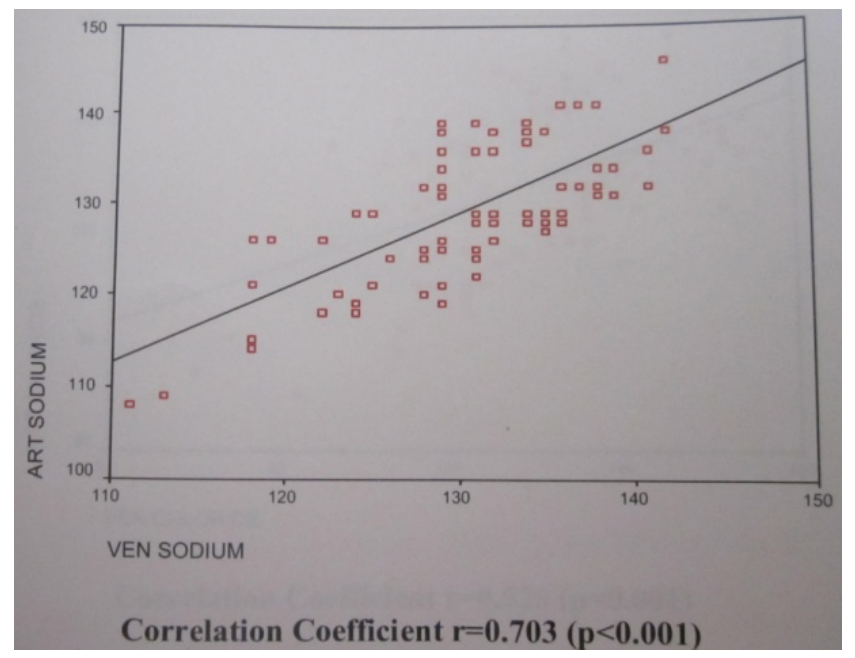

Figure 5. Correlation of arterial and venous sodium

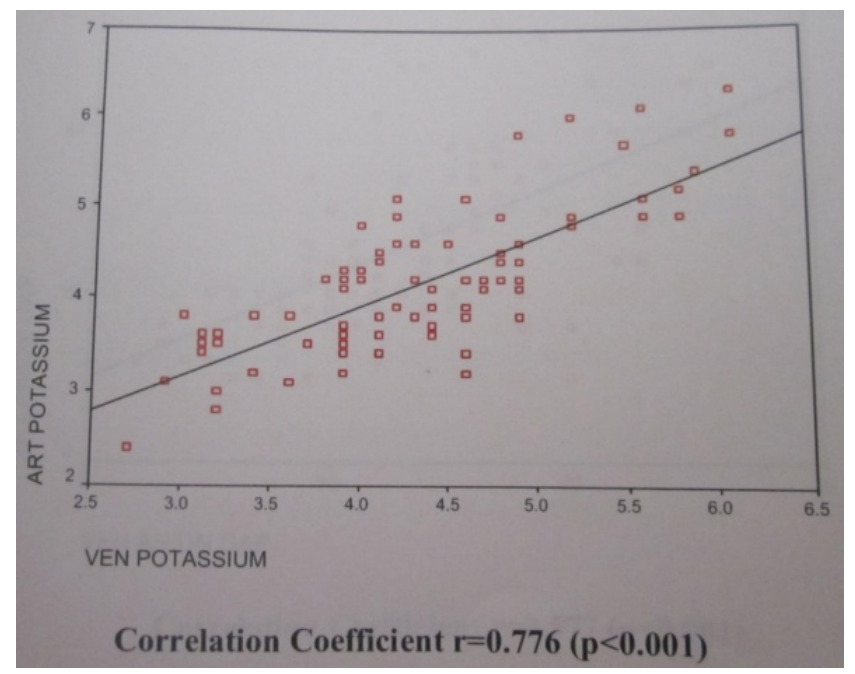

Figure 6. Correlation of arterial and venous potassium 


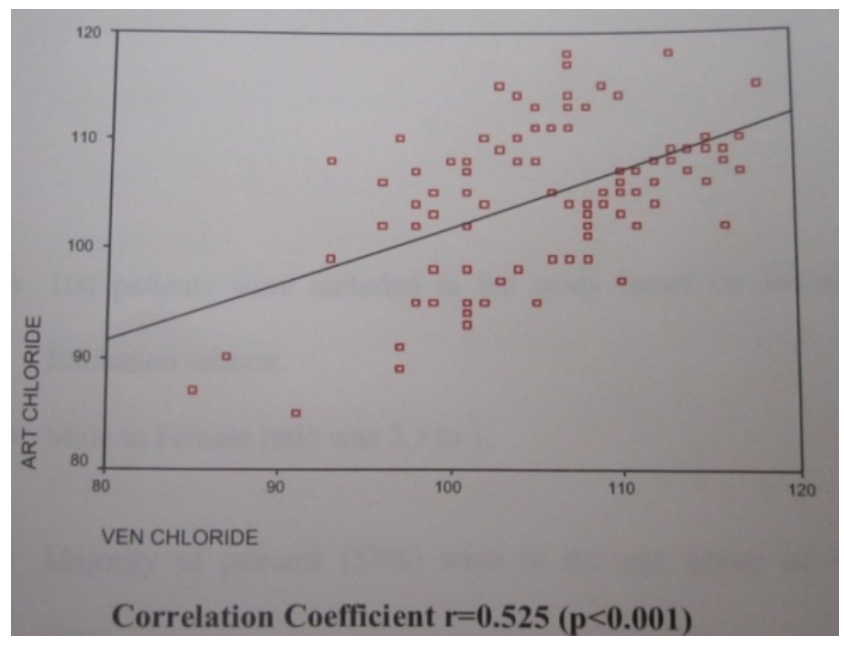

Figure 7. Correlation of arterial and venous chloride

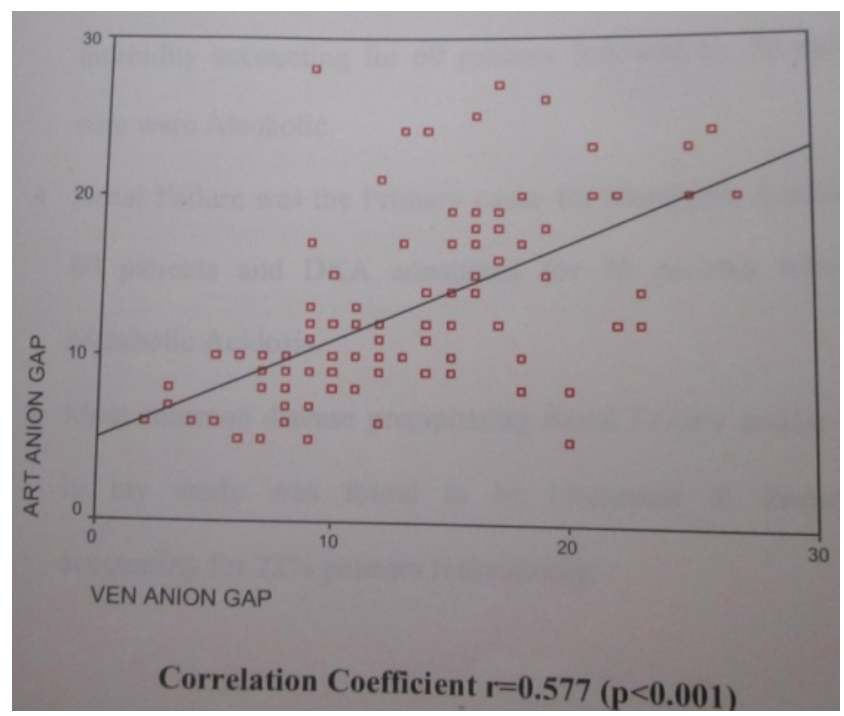

Figure 8. Correlation of arterial and venous anion gap

Arterial blood gas analysis is a useful tool for determining the acid base and respiratory status of critically ill patients.
Venous blood gas analysis has got advantages like safety, fewer number of punctures, ease of sampling along with other blood samples at the time of intravenous line insertion etc, $[5,17]$ even though there are some reservations, [18].

Venous blood gas analysis cannot totally replace arterial blood gas, especially in determining pO2 status and for arterial blood pressure monitoring. But given the accuracy of pulse oximetry, VBG analysis may be a safer alternative to $\mathrm{ABG}$ for determining acid base status, reducing the need for frequent invasive arterial sampling.

Arterial and venous values for $\mathrm{pH}$ and $\mathrm{HCO} 3$ showed excellent agreement (TABLE 5) with each other as in earlier studies, $[4,9,10-12,14-18]$.

The mean arterial minus venous difference for $\mathrm{pH}$ was $-0.002^{\mathrm{TABLE}} 5$ in our study, which suggests that VBG $\mathrm{pH}$ values very closely correlate with $\mathrm{ABG} \mathrm{pH}$ values. The previous studies indicated a difference of -0.04 to 0.05 , [9-12,14-18], which also supports VBG substitution for ABG.

In the case of $\mathrm{HCO} 3$, the mean arterial minus venous difference was $-0.11^{\text {TABLE } 5}$. Though the previous study results varied from -1.88 to $-0.52,[4,11,12,14-16,17,18]$, they too indicate that venous bicarbonate can be used as a substitute for arterial bicarbonate.

For $\mathrm{pCO} 2$, the mean arterial minus venous difference was $-2.6^{\text {TABLE } 5}$ whereas previous results ranged from -6.6 to $-3.0,[15-18]$. Hence there is considerable agreement between the two studies.

In the case of lactate, the mean arterial minus venous difference was 0.2. Previous study by Middleton P et al, [12] showed a lactate value of 0.08 .

Arterial and venous blood gases showed highly significant correlation coefficient for $\mathrm{pH}, \mathrm{HCO} 3, \mathrm{pCO} 2$ and lactate $(\mathrm{r}=0.919,0.966,0.967$ and 0.924 respectively with a $\mathrm{p}$ value of $<0.001)$.

Hence, venous blood gas might be used as an ideal alternative to arterial blood gas in the initial management for diabetic ketoacidosis and/or renal failure.

Table 5. Comparison of Arterial \& Venous Blood Gas variables

\begin{tabular}{|c|c|c|c|c|c|}
\hline & $\mathbf{p H}$ & $\mathrm{HCO}_{3}$ & $\mathrm{pCO}_{2}$ & Lactate & \\
\hline ABG & $7.29+/-0.0448$ & $12.12+/-2.61$ & $25.2+/-4.0$ & $5.39+/-1.95$ & \\
\hline VBG & $7.292+/-0.0451$ & $12.23+/-2.55$ & $27.8+/-3.9$ & $5.19+/-1.81$ & \\
\hline \multicolumn{5}{|c|}{ Correlation coefficient between ABG \& VBG } & p value \\
\hline & 0.919 & 0.967 & 0.966 & 0.924 & $<0.001$ \\
\hline$n=100$ & \multicolumn{2}{|c|}{ Renal Failure patients $(n=80)$} & \multicolumn{2}{|c|}{ Diabetic Ketoacidosis patients(n=20) } & \\
\hline \multirow[t]{2}{*}{ ABG } & $62(77.5 \%)$ & $18(22.5 \%)$ & $20(100 \%)$ & & $<0.001$ \\
\hline & NAGMA & HAGMA & HAGMA & & \\
\hline \multirow[t]{2}{*}{ VBG } & $49(61.3 \%)$ & $31(38.8 \%)$ & $2(10 \%)$ & $18(90 \%)$ & \\
\hline & NAGMA & HAGMA & NAGMA & HAGMA & $<0.001$ \\
\hline
\end{tabular}




\section{Limitations}

- Only one paired sample was taken and analyzed. Further studies involving serial paired samples may fetch better results.

- Long period of study over two years can introduce many variables, for example the source of ABG kits used for sample analysis in the hospital lab.

- Patients with metabolic acidosis with $\mathrm{pH}>7.18$ only were studied. Those with lower $\mathrm{pH}$ have to be studied.

- Patients with predominant metabolic acidosis alone were subjected to the study. The extent of correlation in mixed acid base balance has to be studied.

- Utilization of the lab derived serum values of the electrolytes for anion gap determination, rather than the ABG analyzer derived electrolyte values, could have possibly been more accurate while determination of the type of metabolic acidosis,ie. whether NAGMA or HAGMA.

\section{Acknowledgements}

1. All the staff of Department of Emergency Medicine and Critical Care, Amrita Institute of Medical Sciences, Kochi.

2. Department of Biostatistics, Amrita Institute of Medical Sciences, Kochi.

\section{No Competing Interests}

\section{Funding-nil}

\section{REFERENCES}

[1] Milzma D, Janchar T :Arterial puncture and cannulation In: Clinical Procedures In Emergency Medicine , $4^{\text {th }}$ Ed, edited by Roberts JR, Hedges JR, Philadelphia, WB Saunders 2004, pp384-400

[2] Mortensen J. Clinical sequelae from arterial needle puncture, cannulation and incision. Circulation. 1967;35:1118-1123

[3] Criscuolo C, Nepper G, Buchalter S. Reflex sympathetic dystrophy following arterial blood gas sampling in the intensive care setting. Chest $108 ; 1995: 578-580$

[4] Kelly AM, McAlpine R, Kyle E. Agreement between bicarbonate measured on arterial and venous blood gases. Emerg Med Australas : 2004;16(5-6):407-409

[5] Darren J, Malinoski MD, Samuel R, Todd. Correlation of central venous and arterial blood gas measurements in mechanically ventilated trauma patients. Arch Surg. 2005; 140:1122-1125

[6] Richard Treger, Shahriar Pirouz, Nader Kamangar, et al. Clin J Am Soc Nephrol 5: 2010:390-394

[7] Brandenburg MA, Dire DH. Comparison of arterial and venous blood gas values in the initial emergency department evaluation of patients with diabetic ketoacidosis. Ann Emerg Med. 1998;31:459-465.

[8] Hale PJ, Nattrass M. A comparison of arterial and nonarterialized capillary blood gases in diabetic ketoacidosis. Diabetes Medicine 1988;5:76-78.

[9] Kelly AM, Mc Alpine R, Kyle E. Venous pH can safely replace arterial $\mathrm{pH}$ in the initial evaluation of patients in the emergency department. Emerg Med J. 2001;18(5):340-342

[10] Ma OJ, Rush MD, Godfrey MM, et al. Arterial blood gas results rarely influence emergency physician management of patients with suspected diabetic ketoacidosis. Acad Emerg Med 2003;10(8):836-841

[11] Gokel Y, Paydas S, Koseoglu Z, et al. Comparison of blood gas and acid base measurements in arterial and venous blood samples in patients with uremic acidosis and diabetic ketoacidosis in the emergency room. Am $J$ Nephrol. 2000;20(4):319-323

[12] Middleton P, Kelly AM, Brown J, et al. Agreement between arterial and central venous values for $\mathrm{PH}$, bicarbonate, base excess, and lactate. Emerg Med J. 2006;23:622-624

[13] Chu YC, Chen CZ, Lee CH, et al. Prediction of arterial blood gas values from venous blood gas values in patients with acute respiratory failure receiving mechanical ventilation. J Formos Med Assoc 102;2003:539-543

[14] Brandenburg MA, Dire DJ. Comparison of arterial and venous blood gas values in the initial emergency department evaluation of patients with diabetic ketoacidosis. Ann Emerg Med 31: 1998,459-465

[15] Ak A, Ogun CO, Bayir A, et al: Prediction of arterial blood gas values from venous blood gas values in patients with acute exacerbation of chronic obstructive pulmonary disease. Tohoku J Exp Med 210:2006,285-290.

[16] Malatesha G, Singh NK, Bharija A, et al. Comparison of arterial and venous $\mathrm{pH}$, bicarbonate, $\mathrm{pCO} 2$ and $\mathrm{pO} 2$ in initial emergency department assessment. Emerg Med $J$ 24(8):2007,569-571

[17] Kelly AM, Kyle E, McAlpine R. Venous pCO2 and pH can be used to screen for significant hypercarbia in emergency patients with acute respiratory disease. J Emerg Med 22: 2002,15-19

[18] Rang LC, Murray HE, Wells GA, et al. Can peripheral blood gases replace arterial blood gases in emergency department patients? CJEM 4:2002,7-15 